\title{
Influence of Irrigation Modalities (Irrigation Management and Dryland), Fruit Ripening, and Cultivation Modality (Organic and Conventional) on Quality and Chemosensory Profile of Hojiblanca and Picual Extra Virgin Olive Oils
}

\author{
Rocio Ríos-Reina, Francisco Camacho, M. Lourdes Morales, Brígida Jiménez-Herrera, \\ and Raquel M. Callejón*
}

\begin{abstract}
A study with controlled field and authentic samples of olives, obtained in similar conditions of soil, climate, region, harvest, and with the same cultivation techniques and considering simultaneously different agronomic factors (olive variety, fruit ripening degree, irrigation, and organic or conventional production system) is performed to evaluate their influence on quality and added value of extra virgin olive oil (EVOO). Agronomical and physicochemical parameters, polyphenols, tocopherols, and fatty acid composition and volatile and sensory profiles are determined in Hojiblanca and Picual VOOs obtained from different fruit ripening degrees and different cultivation modalities (conventional with and without irrigation, and organic with irrigation). Among volatile compounds, 1-hydroxy-2-propanone, (E)-linalool oxide, and 2-acetylfuran are described for the first time in EVOO. The variable that most influences the chemosensory composition of EVOOs is the variety, followed by the stage of ripeness, and, within each variety, the cultivation modality. Organic irrigation differ from conventional modalities, showing significant differences in acidity, stability, tocopherol and polyphenol contents, fatty acid composition, and sensory attributes.

Practical Applications: Results are of great importance, due to their applicability to the EVOO sector, allowing one to know the qualitative, chemical and organoleptic differences between organic and conventional EVOO, and factors that improve the quality and performance of EVOO.
\end{abstract}

\section{Introduction}

Virgin olive oil (VOO) production is mainly concentrated in Mediterranean countries, Spain being the leader in both olive

Dr. R. Ríos-Reina, F. Camacho, Prof. M. L. Morales, Dr. R. M. Callejón Área de Nutrición y Bromatología, Dpto. de Nutrición y Bromatología,

Toxicología y Medicina Legal

Facultad de Farmacia, Universidad de Sevilla

C/P. García González n², Sevilla E-4 1012, Spain

E-mail: rcallejon@us.es

Dr. B. Jiménez-Herrera

Department of Technology, Postharvest, and

Food Industries, IFAPA "Cabra" Centre

Institute for Research and Training in Agriculture and Fisheries

Ctra. Cabra-Doña Mencía, KM. 2.5, Cabra, Córdoba 14940, Spain

DOI: $10.1002 / e j \mid t .202000375$ grove surface and olive oil production. ${ }^{[1]}$ VOO, and especially extra virgin olive oil (EVOO), is a product that is increasingly appreciated by consumers for its organoleptic, nutritional characteristics, and high quality and benefits for human health. ${ }^{[2,3]}$

The European Union, the Codex Alimentarius and the International Olive Council have different regulations to classify olive oil according to their quality. ${ }^{[4]}$ As is well known, lipid composition is one of the main contributors to nutritional and functional quality, due to the high proportion of monounsaturated fatty acids (MUFA) of olive oil. Polyphenols also have an important role in quality since they are responsible for organoleptic characteristics, stability, and health benefits. In fact, olive oil is the only food product that has an authorized health claim on polyphenols: ${ }^{[5]}$ "olive oil polyphenols contribute to the protection of blood lipids from oxidative stress." Moreover, olive oil not only has a health claim on olive oil polyphenols, it also has another on unsaturated fatty acids.

Other essential compounds in olive oil quality are volatile compounds since they contribute greatly to the overall aroma and flavor. ${ }^{[6-8]}$

Quantitative and qualitative chemical composition of VOO is affected by many factors such as agronomical and technical factors, having a great impact on its quality. They mainly include the genetic factor such as olive variety; the environmental factors, such as pedoclimatic factor related to the geographical area, maturation degree of the fruit, irrigation, crop season or the agronomical practices used (e.g., conventional or organic practices); and technological factors, such as the conditions of oil extraction process. ${ }^{[9-13]}$

Although previous studies have shown that the olive variety and fruit ripening stage have a greater effect on nutritional and physical-chemical parameters than the cultivation modality, ${ }^{[14]}$ irrigation seems to influence the composition and organoleptic characteristics of olive oil ${ }^{[15]}$ although its level on VOO quality is not yet clear and is still controversial. ${ }^{[16-20]}$ 
Another particularly important factor to consider is the type of farming, due to the increase in demand for organic products by consumers and the strict regulation of the application of certain chemical products to crops, such as insecticides, fungicides, or herbicides. ${ }^{[21]}$ However, despite the increase in the surface area in organic agriculture olive groves in Spain, and the potential adulterations and frauds in this kind of product, there is still a lot of ignorance about how the type of crop, organic or conventional, affects chemical composition since to date, few comparative studies have been performed between organic and conventional olive oils. ${ }^{[10,14,22,23-25]}$ Indeed, in some cases, such studies have obtained contradictory and inconclusive results due to the experimental design not considering factors such as variety, year of harvest, place of production, same soil type, ripeness of the fruit at the time of harvest, the same cultivation techniques, etc. In other words, these studies were not performed using controlled and comparable samples obtained under the same conditions in which the only variable was the crop type.

Therefore, a study with controlled field samples, obtained under the same conditions, considering simultaneously different agronomic factors (olive variety, fruit ripening degree, irrigation, and organic or conventional) would represent an advance in the knowledge on EVOO, preventing fraud and providing information to the industry, producers, and consumers, on the quality and added value of these products.

In this context, the aim of this work is to study simultaneously the influence of irrigation and production system (organic and conventional) on the quality of EVOOs (including total phenols, tocopherols, fatty acid composition, and volatile and sensory profile) from Hojiblanca and Picual varieties and different fruit ripening degree, obtained under similar conditions.

\section{Experimental Section}

\subsection{Chemicals}

The analytical standards of fatty acids, tocopherols, volatile, and phenolic compounds were of high purity (>95\%) and obtained from commercial sources (Merck, Darmstadt, Germany; SigmaAldrich, Madrid, Spain; Fluka, Madrid, Spain). Water was obtained from a Milli-Q purification system (Millipore, USA). A series of C10 to C40 straight-chain n-alkanes (50 mg L-1in nhexane) purchased from Fluka was used to calculate linear retention index (LRI). All the solvents used were of analytical or HPLC grade (Sigma-Aldrich).

\subsection{Olive Fruit Samples}

Olive fruits were collected from olive trees of two of the varieties most cultivated in Andalusia, the Picual and Hojiblanca varieties, cultivated in three modalities: conventional with irrigation farming (CI), organic with irrigation farming (OI) and conventional without irrigation or dryland farming (CD); and were harvested at four different stages of ripening. The olive trees cultivated by all three modalities were located in two orchards, $17 \mathrm{~km}$ apart from one other, at similar altitudes (approximately $300 \mathrm{~m}$ above sea level) and with similar weather conditions. Hence, both areas have a continental Mediterranean climate with dry summers and mild winter. Rainfall occurs from autumn to spring, with a mean annual rainfall of $400 \mathrm{~mm}$. The average annual temperature is $17{ }^{\circ} \mathrm{C}$, reaching $-1.3{ }^{\circ} \mathrm{C}$ in winter and $43{ }^{\circ} \mathrm{C}$ in summer. Soils have low depths, being mainly over limestone and siliceous stones. They have a loamy texture and an alkaline $\mathrm{pH}$ (in the 8-8.5 range). Thus, the olive trees cultivated with conventional modality (dryland and irrigation farming) were located at the Agricultural Research Training Centre in "Cabra" in the province of Cordoba, Spain, while olive trees cultivated with organic modality (irrigation farming) were situated in "Baena" in the province of Cordoba, Spain. The irrigation modalities were performed using a localized irrigation system with four drip nozzles with an application of $40 \mathrm{~L}$ per day for each tree, delivering a total of $1500 \mathrm{~m}^{3}$ per hectare.

Ten olive trees were randomly selected (always among the most loaded to guarantee sampling) of the Picual variety and conventional irrigation modality, 10 trees of the Picual variety and conventional dryland modality, and 10 trees of the Picual variety and organic irrigation modality. The same selection was carried out for olive trees of the Hojiblanca variety (10 conventional with dryland, 10 conventional with irrigation, and 10 organic with irrigation).

Olive sampling was done by randomly hand-picking only healthy fruits (without any type of infection or physical damage), every 2 weeks, beginning in October 2016 and ending in December 2016, and comprising different harvest periods. It conforms a total of 4 ripening stages: 22 from October (phase I), 3 from November (phase II), 19 from November (phase III) and 2 from December (phase IV).

The ripening index (RI) of each harvest was determined according to the methodology proposed by Uceda and Frias. ${ }^{[26]}$ The fruit RI values for each modality are shown in Table S1 (Supporting Information).

\subsection{Agronomical Indices}

\subsubsection{Weight of 100 Fruits}

The fruit weight was determined as the weight of 100 drupes randomly picked from aliquots of samples that had been previously homogenized.

\subsubsection{Resistance to Detachment (RD)}

This parameter was evaluated using a dynamometer (Correx, Switzerland) measuring the force (in grams) necessary to break the fruit peduncle and detach it from the branch.

\subsubsection{Oil Content (CAH and CAS) and Humidity Content}

The sample humidity content was determined according to the UNE Standard Spanish method. ${ }^{[27]}$ Oil content was determined by the Soxhlet method using hexane. ${ }^{[28]}$ The oil content has been expressed in two ways: the first one referred to the wet weight of the paste $(\mathrm{CAH})$ and the other referred to the weight of the dry paste (CAS). 


\subsection{Oil Samples}

Three representative olive samples, each weighing a minimum of $1 \mathrm{~kg}$, were processed and the corresponding EVOOs were obtained using an Abencor milling system (Abengoa S. A., Sevilla, Spain). The olive fruits were milled using a stainless-steel hammermill equipped with a $5 \mathrm{~mm}$ sieve that was operated at $3000 \mathrm{rpm}$. The resulting olive paste was immediately kneaded in a mixer at $50 \mathrm{rpm}$ for $30^{\circ} \mathrm{C}$, with hot water added at $20 \mathrm{~min}$. Centrifugation of the kneaded olive paste was performed in a basket centrifuge at $3500 \mathrm{rpm}$ for $1 \mathrm{~min}$. After centrifugation, the oil was decanted and stored in amber glass bottles at $4{ }^{\circ} \mathrm{C}$ in darkness and without headspace until analysis.

\subsection{Stability}

The oxidative stability was determined according to the Rancimat method ${ }^{[29]}$ using a Rancimat apparatus (Metrohm, Herisau, Switzerland).

\subsection{Analytical Indices}

Free acidity, peroxide value, and UV spectrophotometric indices (K232, K270) were evaluated according to the official methods described in Regulation EEC 2568/91 and subsequent amendments of the Commission of the European Union. ${ }^{[4]}$ All parameters were determined in triplicate for each sample.

\subsection{Fatty Acid Analysis}

The methodology used was a modification of the provisions of Commission Regulation (EEC) 2568/91. [4] The supernatant solution containing the fatty acid methyl esters was injected into an Agilent 6890 series gas chromatograph equipped with an automatic sampler (Agilent 7683), split-splitless injector, flame ionization detector (FID) and HP Chemstation (Agilent Technology) program. The fatty acids were quantified in percentages. Their identifications were made by comparing retention times with a standard solution of the methyl esters of pure fatty acids.

\subsection{Polyphenols and Tocopherols Analysis}

The content of tocopherols was analyzed according to the IUPAC 2432 method $^{[30]}$ by high-performance liquid chromatography (HPLC) using a Perkin-Elmer liquid chromatograph equipped with an isocratic LC200 pump and an LC295 UV-Vis detector. The results were expressed as mg of tocopherol per $\mathrm{kg}$ of oil. ${ }^{[31]}$

The determination of total polyphenols was performed following the method adopted by the International Oleic Council for the chemical analysis of the biophenols of olive oil. This technique is based on the extraction of the minor polar components of a phenolic nature directly from olive oil by means of a methanolic solution and its subsequent quantification by HPLC with a UV detector at $280 \mathrm{~nm}$, using syringic acid as the internal standard. The total content of phenolic components (natural or oxidized derivatives of oleuropein and ligustroside, in lignans, in flavonoids and in phenolic acids) is expressed in $\mathrm{mg} \mathrm{kg}^{-1}$ of tyrosol.

\subsection{Sensory Analysis}

The organoleptic assessments of this study were carried out by the tasting panel of the Regulatory Council of the Protected Designation of Origin "Priego de Córdoba," in accordance with the IOC standards. The tasting panel was formed by a group of tasters, between 8 and 12, previously selected and trained according to the techniques pre-established by the IOC/t.20/ Doc $n^{\circ} 15$ / Rev.2 September 2007, and according to the European Regulation CE 640/2008. ${ }^{[32]}$ The sensory profile of each EVOO sample was expressed as the median value for each descriptor. The tasters evaluated directly or retronasally aromatic olfactory sensations, such as olive fruity, green leaf/fresh-cut grass, apple, almond, artichoke, and other positive attributes, such as gustatory sensations (bitterness and sweetness) and tactile/kinaesthetic sensations (pungency). The tasters had to rate the intensity of the different descriptors on a continuous scale.

\subsection{Volatile Analysis}

The determination of volatile compounds was carried out by gas chromatography coupled to mass spectrometry (GC-MS), following and adapting the method proposed by Callejon et al. ${ }^{[33]} 2 \mathrm{~g}$ of olive oil was placed in headspace vials of $20 \mathrm{~mL}$ capacity from Gerstel (Müllheim and der Ruhr, Germany), and after inserting the twister in a glass insert, it was tightly closed and heated in a thermostatic bath at $60^{\circ} \mathrm{C}$ for $1 \mathrm{~h}$. GC-MS analysis was performed by a 6890 Agilent GC system coupled with a quadrupole mass spectrometer Agilent 5975inert and equipped with a Gerstel Thermo Desorption System (TDS2) and a cryo-focusing CIS-4PTV injector (Gerstel). The quadrupole, source, and transfer line temperatures were maintained at $150^{\circ} \mathrm{C}, 230^{\circ} \mathrm{C}$, and $280^{\circ} \mathrm{C}$, respectively. The electron ionization mass spectra in the full-scan mode were recorded at $70 \mathrm{eV}$ with the electron energy in the range of 29 to $300 \mathrm{~m} / \mathrm{z}$.

The identification of volatile compounds was based on mass spectrum matching to the NIST 98 library and confirmed by the available retention index of standards (RIs). When standards were not available, the compounds were identified by computer matching to the reference mass spectra from the NIST library and by the comparison of their RIs with the RIs obtained with standards that have been reported in the literature. The remaining compounds were tentatively identified by computer matching to the reference mass spectra from the NIST library and/or through comparisons of their RIs with those of online databases (Flavornet; Pherobase) and the literature. RIs were calculated by using the retention times of n-alkanes obtained under identical analytical conditions, according to the literature. ${ }^{[34]}$ The samples were analyzed by triplicate.

\subsection{Statistics}

All statistical analyses and data treatments were carried out by using the PLS_Toolbox 7.9.5 working under MATLAB environment. The significance of the differences between the means at the $5 \%$ level was determined by performing an analysis of variance (ANOVA) of a factor and the Tukey "PosHoc" test. 

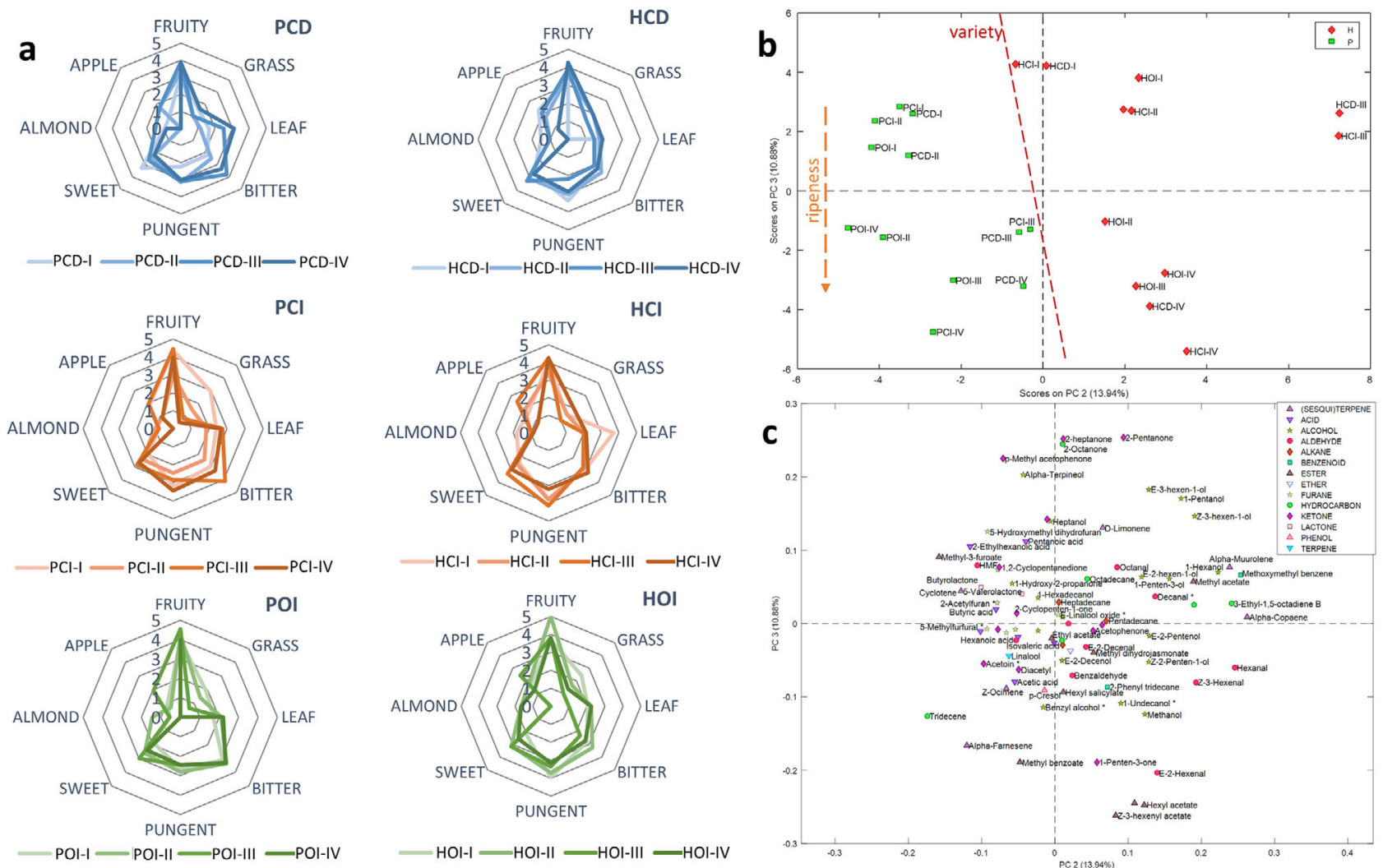

Figure 1. Spider charts obtained by the sensory analysis of the a) olive oils, and b) scores and c) loadings plots obtained by a PCA carried out with the areas of the volatile compounds identified in all the samples according to the variety (Picual-P or Hojiblanca-H), cultivation modality (conventional with irrigation farming $(\mathrm{Cl})$, organic with irrigation farming $(\mathrm{OI})$, and conventional without irrigation or dryland farming $(\mathrm{CD})$ ) and ripening stage $(\mathrm{I}$, II, III, IV).

Principal component analysis (PCA) was applied to the different parameters studied as well as to the global parameters of analyses, in order to study the influence on the olive oil according to the different cultivation modalities (dryland, conventional irrigation, and organic irrigation), the different moments of fruit harvesting and the different varieties. Autoscaling and group-scaling were applied for the individual and the global data matrices, respectively.

\section{Results and Discussion}

\subsection{Chemosensory Evaluation}

The sensory analysis and therefore, the volatile profile of olive oils has an important role for the quality and properties of the commercialized product. For this reason, a chemosensory evaluation was performed in detail. Figure 1 shows, on the left side, the spider charts obtained by the sensory analysis of the olive oils according to the variety, cultivation modality, and ripening stage (Figure 1a), and on the right side, the scores and loadings plot obtained by a PCA carried out with the areas of the volatile compounds identified in the samples (Figure 1b,c).

Concerning the sensory profiles of the olive oil, it can be seen how they vary as ripening progress (Figure 1a), according to that reported by several authors. ${ }^{[10,35]}$ Thus, for both varieties and modalities, the sweet attribute showed an increasing trend through ripening, according to the literature ${ }^{[36,37]}$ and reaching, in general, the maximum values in stage III. Bitter and fruity attributes also reached maximum values in stage III of Picual oils, according to Jiménez et al. ${ }^{[37]}$ As other authors reported, ${ }^{[36]}$ the grass, apple, and almond attribute tended to decrease with ripening in both varieties, reaching the lowest scores in the last ripening stages. The remaining attributes did not show a clear trend with ripening, varying according to the variety or the cultivation modality.

Regarding the variety, there were also some differences in their sensory profile. Thus, in general and considering mean values, the Hojiblanca variety was more pungent, grassier, and sweeter than the Picual, which reached greater values for the bitter, apple, almond, and leaf attributes. The sensory differences between these varieties were also observed by other authors. ${ }^{[10,38]}$ The fruity descriptor showed similar values in both varieties. According to Dabbou et al., ${ }^{[38]}$ the fruity attribute is a reflection of the raw material from which the oil is obtained and it is fundamental in the VOO aroma, since the aroma or flavor of VOO is produced by the balance between green and fruity notes.

With respect to the cultivation modality, there were fewer differences in general. Hence, the dryland modality (CD) presented lower mean scores for most of the sensory attributes, standing out for a higher sweetness, in accordance with other authors. ${ }^{[38]}$ In comparison, the conventional oils obtained under irrigation $(\mathrm{CI})$, reached higher values in both varieties for the 
fruity, pungent, bitter, grass, and leaf attributes, especially in stage III (Figure 1a). These results are also in accordance with Rosati et al., ${ }^{[39]}$ Jiménez et al., ${ }^{[10]}$ and Dabbou et al. ${ }^{[38]}$ who observed an increase in these attributes when increasing the irrigation level. The organic oils (OI) showed, in general, higher values for bitterness and fruity attributes, mainly in the second ripening stage. This is due to the higher presence of phenols and volatile compounds synthesized throughout the lipoxygenase (LOX) pathway, which are responsible for bitter and olive fruity sensory attributes, respectively. ${ }^{[10,40]}$ The higher presence of these attributes favors the quality of these oils in comparison to the oils obtained by the other modalities. ${ }^{[41]}$

The differences between varieties and modalities can be clearly observed by looking at the ripening stage I. Hence, PCD oil is highlighted by its sweet notes, PCI by its pungent, herb, fruity, and apple notes, and POI oil by its bitterness (Figure 1a). This was expected, since, as mentioned above, oils from organic farming reached higher amounts of total phenols (Table S2, Supporting Information), which has shown to be related to the bitter attribute. ${ }^{[42]}$ On the other hand, Hojiblanca in this first stage is highlighted by higher leaf notes in HCI, more herb notes in HOI and sweet and apple notes in HCD oils. Moreover, stage III was the one that showed fewer differences among the different modalities.

In general, the better sensory scores were obtained for the ripening stages III and IV except for the organic oils whose better sensory profiles were obtained in stages II and III. This difference is in accordance with the differences discussed above regarding the ripening of the organic fruits, which matured earlier than fruits of the other modalities.

Table S3 in Supporting Information showed the mean of total peak areas obtained for the volatile compounds detected, their standard deviation and the statistical results obtained by carrying out an ANOVA regarding the variety, ripening stage, and cultivation modality.

In our study, a total of 85 volatile compounds were determined for both varieties, all cultivation modalities and ripening stages, 3 of which are described and identified for the first time in EVOOs (1-hydroxy-2-propanone, (E)-linalool oxide, and 2-acetylfuran). Within the 85 volatile compounds determined, 15 compounds were alcohols, 14 ketones, 10 furans, 8 aldehydes, 8 terpenes, 8 hydrocarbons, 7 esters, 7 acids, 3 lactones, and 5 compounds classified as "other."

In general terms, regarding the values of total peak areas obtained for the total volatile compounds in both varieties (Table S3, Supporting Information), Hojiblanca seemed to have a significantly higher value of volatile compounds than Picual samples, clearly observable in the alcohols, aldehydes, and esters families. However, Hojiblanca samples showed lower values for acids, furans, and hydrocarbons than Picual. Regarding the modalities, EVOOs from conventional cultivation (irrigation-CI- and dryland-CD) had higher total areas for the total volatile composition than the organic EVOOs, except in stage I of both varieties, where the opposite was observed. Moreover, in conventional EVOOS of both varieties, the total areas of most of the chemical families followed the same trend of increasing with ripening, showing their maximum in Picual IV and Hojiblanca III. These results matched the results obtained by Jimenez et al. ${ }^{[10]}$ However, organic samples showed differences between Picual and
Hojiblanca varieties, since the total area of volatile compounds in Picual significantly increased with ripening while it decreased in Hojiblanca.

Regarding the irrigation effect, although both conventional modalities showed an increasing trend with ripening, in general, it was observed that those EVOOs from both varieties under irrigation cultivation (PCI and $\mathrm{HCI}$ ) reached higher values of total volatile compounds than those under dryland cultivation (PCD and HCD) (Table S3, Supporting Information). According to the literature, there is no clear trend or effect with regard to the change in total volatile compounds as a function of the irrigation regime. ${ }^{[38]}$ As is well known, the major volatile compounds reported in virgin olive oils are the C6 and C5 compounds derived from linoleic and linolenic acids through the lipoxygenase (LOX) pathway, which takes place during the crushing of the olive fruit and olive paste malaxation. ${ }^{[6,43]}$ These compounds, referred to as LOX compounds, are mainly aldehydes, alcohols, esters, hydrocarbons, and ketones, which are responsible for the characteristic and positive green sensory notes. This group of compounds, contrary to that observed by Jiménez et al. ${ }^{[10]}$ increased through the fruit ripening process in conventional EVOOs (dryland and irrigation), reaching the highest values in stages III and IV in those from Hojiblanca and Picual varieties, respectively (Figure S1, Supporting Information). However, organic EVOOs did not present a clear trend through fruit ripening. Ninfali et al. ${ }^{[44]} \mathrm{com}$ pared conventional and organic olive oils across a 3 year study and a nonconsistent trend was observed because the volatile composition depends on a variety of factors, including cultivar, climate, soil type, nutrient and water availability, duration, and conditions of storage and the differences related to the cultivation methods may be difficult to be observed. ${ }^{[45]}$ Moreover, regarding the irrigation effect on LOX compounds, no significant differences were observed between the irrigated and dryland samples.

As shown in Table S3 (Supporting Information), most of the volatile compounds showed significant differences between total areas. Hence, a PCA was developed in order to better study the differences between varieties, cultivation modalities, and ripening stages considering the volatile profile. The scores and loadings plots obtained by the second and third PCs (explaining $24.82 \%$ of variance) were reported in Figure 1b,c (on the right side of Figure 1). Hence, it could be clearly observed that the volatile composition differentiated the samples mainly through their variety (explained by PC2). This result was expected since various authors have reported the genetic effect related to cultivar as one of the most important aspects of the volatile composition of olive oils. ${ }^{[46]}$ Moreover, differences through the ripeness stage (explained by PC3) could be observed. Thus, the first ripening stages I and II were placed on the upper side of the scores plot (positive values of PC3) and the latest stages on the lower side (negative values of PC3). In addition, in both varieties, but mainly in Picual, it could be observed that in the first stages there were not many differences regarding the cultivation modalities, and the samples appeared more grouped. However, as fruit ripening increased, a greater difference in the volatile composition was generated, especially in the case of organic farming with irrigation (OI).

Within the family groups with the highest number of compounds, the alcohol family was the majority group followed by ketones and aldehydes. Alcohols have been described as the class 

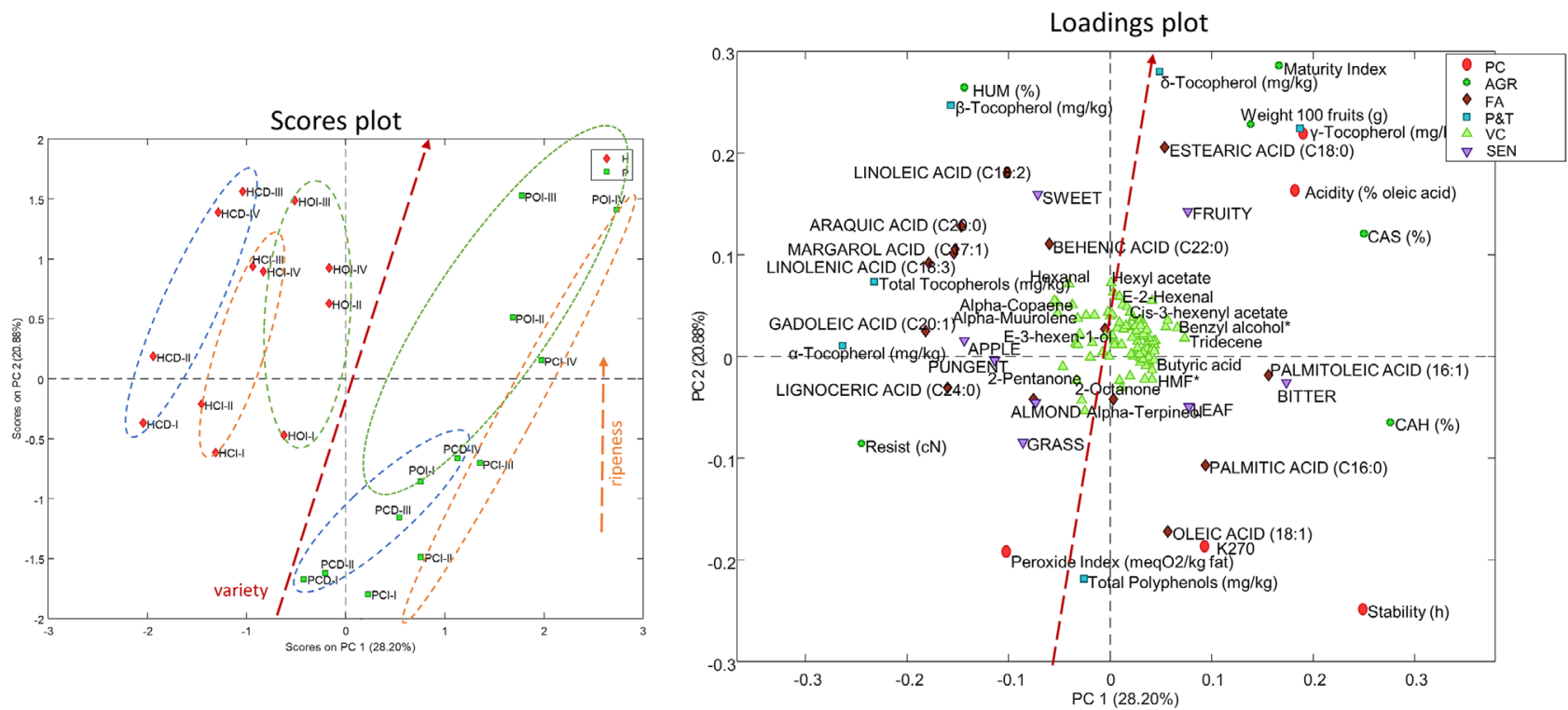

Figure 2. Scores and loadings plots of the PCA model obtained with the total of parameters (physicochemical (PC), agronomical (AGR), fatty acids (FA), polyphenols and tocopherols (P\&T), volatile compounds (VC) and sensory scores (SENS) and samples according to the variety (Picual (P) or Hojiblanca $(\mathrm{H})$ ), cultivation modality (conventional with irrigation farming $(\mathrm{Cl})$, organic with irrigation farming $(\mathrm{OI})$ and conventional without irrigation or dryland farming (CD)) and ripening stage (I, II, III, IV)) analyzed.

with the largest variety of volatile compounds in olive oils in qualitative terms. ${ }^{[38]}$ In our study, most of them proved to be more related to the Hojiblanca variety (Figure 2c), being 1-penten-3ol, 1-pentanol, 1-hexanol, (E)-3-hexen-1-ol, (Z)-3-hexen-1-ol, and (E)-2-hexen-1-ol more related to the first fruit ripening stages and ethanol, methanol, (E)-2-pentenol, (Z)-2-penten-1-ol, (E)-2decenol, and 1-undecanol to the last maturity stages.

Regarding the cultivation modalities, the significant differences in alcohols were observed in stages III and IV of Hojiblanca oils. Thus, in Hojiblanca variety, in stage III the organic samples presented significant lower areas of alcohols than the conventional ones while in stage IV alcohols highlighted in the organic oils, according to Jiménez et al. ${ }^{[10]}$ Comparing the conventional modalities of the Hojiblanca variety, a significant effect of the irrigation regime was observed in stage III, reaching higher values of alcohols in the rainfed samples. This result was in concordance with Sanchez-Rodríguez et al. ${ }^{[47]}$ who found an increase in alcohol concentration in all stressed olive oils due to a deficit irrigation treatment. In Picual, significant differences in the alcohol total areas among the three modalities were not observed at any ripening stage.

Within the ketones, the second group with the highest number of compounds, significant differences among the cultivation modalities were not observed at any stage. 2-Pentanone, which has been recognized as one of the main compounds responsible for fruity notes, ${ }^{[47]}$ showed different values between both varieties, mainly in the first stages, reaching the Hojiblanca variety higher peak areas. Hence, according to that, it could be related to the remarked fruity notes of Hojiblanca oils in the first stages (Figure 1a).

Aldehydes seemed to be more present in the last stages of both varieties (Figure $2 \mathrm{~b}, \mathrm{c}$ ), being consistent with the literature. ${ }^{[10]}$ Thus, the furanic aldehydes such as 3-furaldehyde, furfural, and methyl furfural were more related to Picual oils of the last stages, and hexanal, (Z)-3-hexenal, (E)-2-hexenal, benzaldehyde, (E)-2decenal of Hojiblanca oils of the last stages. Other authors have also demonstrated that (Z)-2-hexenal, connoted by a fruity note, and (Z)-3-hexenal, with a green odor contribute to the discrimination at the ripening stage. ${ }^{[48]}$ Moreover, according to Angerosa et al., ${ }^{[49]}$ hexanal, (Z)-3-hexenal, and (E)-2-hexenal have proved to be one of the most important contributors to high quality of EVOOs. However, it should be also highlighted that although hexanal has been related to green apple and grass sensory descriptors, allowing the differentiation of EVOOs from the rest of the categories, this compound has also been related to a mustinesshumidity, fusty, winey-vinegary, or rancid defect, depending on its concentration. ${ }^{[50]}$ Moreover, (E)-2-hexenal, related to green notes, ${ }^{[38]}$ can be highlighted for its high areas in both varieties in the last ripening stages, in accordance with other authors. ${ }^{[12]}$ In addition, our results were also consistent with the literature, showing that, especially in the Picual variety, irrigated samples exhibited higher areas of (E)-2-hexenal and hexanal than the rainfed ones. ${ }^{[12,38]}$

Finally, the remaining chemical classes, with lower number of compounds than the other groups, could be considered as minor compounds, as other authors have indicated. ${ }^{[38]}$ Within them, esters were more present at the last stages of the Hojiblanca variety such as 1-methoxyhexane, hexyl acetate, methyl dihydrojasmonate, 1-methoxy-(Z)-3-hexene and (Z)-3-hexenyl acetate. This last compound, particularly correlated to sensory attributes like green leaves, could be highlighted due to it having proved to be relevant in the differentiation between non-defective (EVOO) and defective (non-EVOO) olive oil samples, being present in more concentration in EVOO samples. ${ }^{[50]}$ The reason for its interest relies on its odor threshold. Thus, (Z)-3-hexenyl acetate has a much lower odor threshold concentration (between 1 and $2 \mu \mathrm{g}$ 
$\left.\mathrm{L}^{-1}\right)$ than its corresponding alcohol, (Z)-3-hexen-1-ol (50-70 $\mu \mathrm{g}$ $\left.\mathrm{L}^{-1}\right),{ }^{[51]}$ which means that in low concentrations it could provide important green notes to the olive oil, useful for the sensory differentiation of EVOOs.

In the Picual variety, some furans and acids (2-methylfurane, 2-acetylfuran, 5-hydroxymethylfurfural, and butyric acid, pentanoic acid and 2-ethylhexanoic acid) highlighted in the first stages, while others such as acetic acid, propanoic acid, and hexanoic acid, which are related to sensory defects, ${ }^{[52]}$ were more present in the last stages. Another volatile compound that has been related to sensory defects is ethyl acetate (winey, vinegary) ${ }^{[50,52]}$ Although this compound has proved to be relevant in the differentiation of EVOO and non-EVOOs, due to it showing more concentration in LOO samples through a GC-IMS analysis, ${ }^{[50]}$ in the present study it showed low areas in general terms for all the samples, so it might not influence the sensory profile.

In summary, we can say that the variety had a major influence on the volatile and sensory profiles in comparison with the cultivation modalities, the differences of varieties being mainly related to a few $\mathrm{C} 5$ and $\mathrm{C} 6$ alcohols and aldehydes, and fruity, bitter, and pungent sensory attributes as has occurred in other studies. ${ }^{[38]}$

\subsection{Overall Evaluation of Quality}

The agronomical and physicochemical parameters and the content of polyphenols, tocopherols, and fatty acids are summarized in Tables S1, S2, and S4 (Supporting Information). According to these results, the first step was to check that all the samples presented certain values below the limits settled for EVOO samples by the International Olive Council standards (IOC, 2013). ${ }^{[4]}$

Thus, as all these parameters have already been studied by other authors in these two varieties, as well as in the different cultivation modalities and different ripening stages, we considered studying them simultaneously in order to make an overall evaluation of how these parameters influence the different varieties, cultivation modalities and ripening stages and the relationships between them. Moreover, it should be remembered that this was the first time that the influence of irrigation and production system (organic and conventional) on the quality of EVOOs from the Hojiblanca and Picual varieties and different fruit ripening degrees, obtained under similar conditions, was also studied simultaneously. For this purpose, a PCA model was applied to the total number of considered parameters and samples analyzed in this study. The corresponding scores and loadings plot are shown in Figure 2.

The scores plot shows, as expected, that the variety was the most influential variable with respect to the irrigation or cultivation modality, being the first principal component ( $\mathrm{PC1}$ with a $28.20 \%$ of total variance), responsible for this differentiation. Thus, samples were grouped according to the variety, Picual samples being placed on the positive side and Hojiblanca samples on the negative side of PC1.

It could also be observed that the second principal component, PC2, which explained the $20.88 \%$ of the total variance, differentiated the samples according to the ripening stage, being the latest stages on the positive PC2 side, and the earliest ones on the negative side, for all the modalities and both varieties. Moreover, a slight difference could also be appreciated between cultivation modalities but within each variety.

Concerning the loadings, varietal differences were mainly related to the higher presence of bitter and leaf sensory attributes, but also to a higher presence of oleic, palmitic, and palmitoleic fatty acids, higher values of acidity, stability, and peroxide index in Picual oils together with the higher values for CAH and CAS of Picual fruits, whereas Hojiblanca olive oil showed a higher presence of apple, pungent and sweet notes, a higher content in tocopherols, linoleic, linolenic, and other fatty acids, and a higher resistance and humidity values in its fruits.

This differentiation also occurred when the different groups of parameters were studied separately, being consistent with the results obtained by other authors that appreciated a higher difference between varieties than between other conditions. ${ }^{[10,14,36-38]}$ Hence, when the total polyphenol and tocopherol content was studied (Table S2, Supporting Information), it did not distinguish EVOOs in accordance with the cultivation modalities, but showed the main differences between varieties (i.e., Hojiblanca showed more content of total tocopherols and Picual more concentration of total polyphenols), in agreement with Jiménez et al. ${ }^{[25]}$

Something similar occurred when the total amount of fatty acids obtained was studied by separately (Table S4, Supporting Information). In general, both varieties clearly showed the predominance of monounsaturated fatty acids (between $55.0 \%$ and $83.0 \%$ of the total thereof), oleic acid being the most abundant fatty acid in all the samples (Table S4, Supporting Information). However, the variety seems to be the most important and determining factor in the differences in fatty acids. Thus, the total content of fatty acids was in general higher in the Hojiblanca samples, except for palmitic and palmitoleic acids whose contents were higher in the Picual variety (Table S4, Supporting Information), as was observed in other studies. ${ }^{[25,36]}$ By the contrary, there was a difference in the oleic acid content: the Picual variety had, in general, $5 \%$ more oleic acid than the Hojiblanca variety, except in organic cultivation (POI) for which both varieties showed similar content with slightly lower values than the other two modalities. ${ }^{[36]}$ Moreover, the palmitic/linoleic ratio, that is related to the oil balance, and oleic/linoleic ratio, related to stability, ${ }^{[53]}$ were greater for the Picual variety than for Hojiblanca in all modalities and ripening stages (Table S4, Supporting Information), in agreement Jiménez et al. ${ }^{[25,36]}$ Therefore, it can be interpreted that the Picual variety generates more balanced and stable oils than the Hojiblanca variety. However, the linoleic/linolenic relation, that is related to the sensory attributes of olive oils ${ }^{[54]}$ (since they generate the most important volatile compounds with "astringent and green" notes through the lipoxygenase pathway), was greater in the Hojiblanca variety, in accordance with other authors. ${ }^{[35]}$

After studying all the samples together, each variety was studied separately by the development of two news PCAs (Figure 3) in order to see the differences more clearly between modalities or ripening. The score plot in this case shows the organic farming (OI) clearly differentiated from the other two conventional modalities (CD and CI) by means of PC2 in both Picual and Hojiblanca PCA models.

By studying the loadings of both PCAs, the organic samples (placed on the negative or positive side of PC2 in the Picual and 

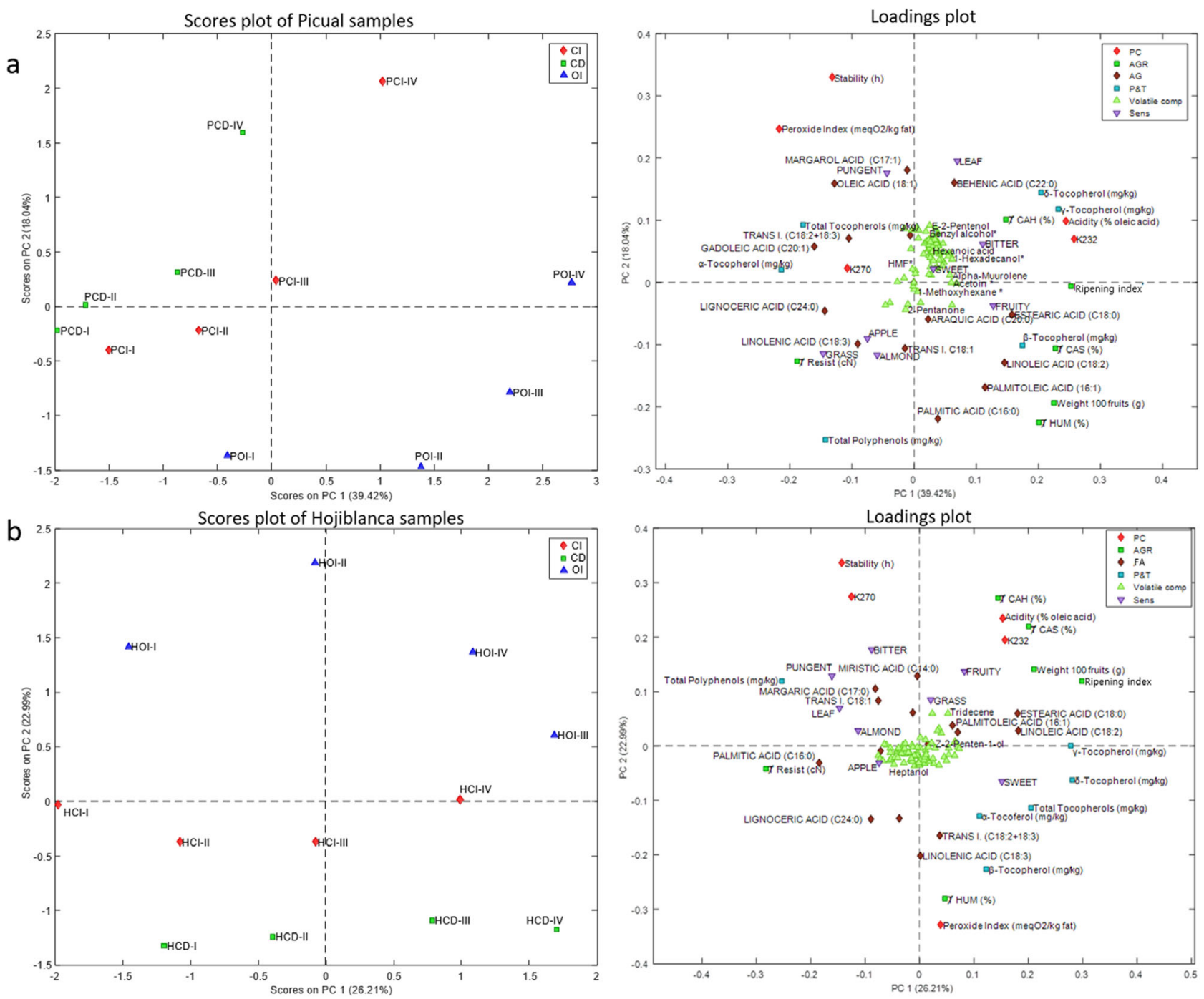

Figure 3. Scores and loadings plots of the PCA analysis developed with the total of parameters analyzed for the total set of samples of the two varieties a) "Picual" (P) and b) "Hojiblanca" $(\mathrm{H})$, cultivated in three modalities: conventional with irrigation farming $(\mathrm{Cl})$, organic with irrigation farming $(\mathrm{OI})$ and conventional without irrigation or dryland farming (CD); and harvested at 4 different stages of maturity (I, II, III, IV).

Hojiblanca PCA, respectively) were characterized in general by a higher weight of 100 fruits, acidity, CAS, K270, and K232 values and ripening index; higher fruity, almond and bitter notes; and a higher concentration of stearic, palmitoleic and linoleic acids than the conventional modalities (dryland and irrigation).

According to these results, a higher relation could be observed between the agronomical and physicochemical parameters above mentioned with the cultivation modality than with the variety (Figure 2). The greater weight of the fruits with irrigation compared to the dryland modality might be due to the additional water supply that they had, ${ }^{[21]}$ usually higher in the organic modality. In consequence, the organic cultivation showed significantly lower values of shedding resistance of its fruits than the other two conventional modalities (Table S1, Supporting Information). The higher values of free acidity in organic olive oils were also observed by other authors, ${ }^{[22]}$ and it was related to a certain infestation or fungal diseases in the olives resulting from the absence of pesticides in this agricultural modality. In contrast, the peroxide index showed in general higher values in the conventional modalities, reaching higher values for dryland farming (CD) than irrigation (CI), while the organic modality showed the lowest values (Table S1, Supporting Information), as occurred in other works. ${ }^{[55]}$ With regard to stability, the cultivation modality, and therefore irrigation, had an opposite influence on both varieties (Table S1, Supporting Information). Thus, POI oils showed the shortest stability times for all stages, while HOI oils had the greatest stability against oxidation in most ripening stages (Table S1, Supporting Information), in accordance with the results reported by Jiménez et al. ${ }^{[14]}$

Moreover, organic modality also showed the highest content of total polyphenols in both varieties (mainly in POI and stage II) as was observed by other authors, ${ }^{[2,10,23,39]}$ followed by the conventional irrigation, ${ }^{[21,56,57]}$ and reaching the lowest values in the dryland modality (Table S2, Supporting Information). In fact, it has been shown that the activity of the enzyme L-phenyllanine ammonia lyase (PAL), responsible for the biosynthesis of 
phenolic compounds, is increased with high level of irrigation. ${ }^{[58-60]}$ However, other authors have reported different or even opposite results, observing no effect, variable effects over years, or even a dependency of the effect on the growing area. ${ }^{[61]}$ Hence, this brings to light that irrigation does not always produce the same effect in the phenolic content of olive oils. Something similar occurred with the tocopherol content, not following a clear trend with fruit ripening, or cultivation modalities, as other authors reported. ${ }^{40]}$

Regarding fatty acids, the conventional modalities were again more similar, although dryland conditions showed higher values than irrigation, and both differing from organic oils. The latter showed lower amounts of oleic acid (as mentioned above) and higher contents of linoleic acid (being statistically significant in the Hojiblanca variety), palmitic and palmitoleic acids (mainly in the Picual variety) and stearic acid than the other modalities (CI and CD). These differences were in accordance with the results of Jimenez et al., ${ }^{[36]}$ but they contrasted with the results obtained by other authors that did not observe differences in fatty acid composition, ${ }^{[62]}$ or even that fatty acid composition in the oils from the irrigation treatments varied with the seasons. ${ }^{[63]}$ Moreover, among the three modalities studied, the highest values of linoleic/linolenic ratio (Table S4, Supporting Information) were reached in those with extra water supply, and among them, being statistically significant in the Picual organic cultivation (POI), and these results were in accordance with those obtained by several authors. ${ }^{[23,36,63]}$

Finally, in both global PCA model (Figure 2) and the individual PCA model for each variable (Figure 3), the ripening effect was observed. Thus, the earliest ripening stages showed higher relation with grass, almond, bitter, and pungent sensory attributes, total polyphenols, stability, and oleic acid; while the latest ripening stages were more related to sweet, fruity, and apple sensory attributes, tocopherols, ripening index, weight of 100 fruits, CAH, CAS, and humidity, as well as acidity and linoleic and linolenic acids. Therefore, these latest stages showed lower values for shedding resistance, peroxide index, and stability.

The CAS, CAH, and humidity parameters could be relevant due to it having been demonstrated that humidity influences the content of phenolic compounds. Thus, other works showed that when humidity increased significantly, phenolic compounds decreased. ${ }^{[40]}$ Regarding the stability of olive oil, our results showed that the oils obtained from olives at more advanced stages of ripening showed lower stability (Table S1, Supporting Information). This trend was also observed in other studies and could be explained by a reduction in water content with ripening. ${ }^{[14,40,64]}$ The resistance to oxidative deterioration is generally attributed to the lipid composition and the antioxidant content (i.e., phenolic compounds). ${ }^{65]}$

Moreover, greater differences could be seen between modalities than between varieties regarding the ripeness degree (Figure 2), with some of the agronomical and physicochemical parameters reaching the highest values in all the ripeness stages of the organic samples (Table S1, Supporting Information), meaning that the organic samples might anticipate a stage of maturity. A common trend was also observed for both varieties and cultivation modalities, going from the negative side of PC1 and PC2, stages I and II, to the positive side of PC1 and PC2, with the highest ripening stages (Figure 3a,b).
Moreover, although the concentration of polyphenols among the ripening stages was different according to the variety (i.e., Picual showed an increase from stage I to II, and then it decreased while Hojiblanca showed a decrease in total polyphenols from stage I to IV) (Table S2, Supporting Information), it follows the same trend already studied in the literature: a progressively increase during ripening, until it reaches a maximum at the "spotted" and "purple" pigmentation stage, after which it decreases, following a similar trend to stability and humidity. ${ }^{[40]}$

Lastly, an influence of ripening in the fatty acid was not clearly observed (Table S4, Supporting Information), remained practically unchanged as ripening progressed, as was also observed by Jiménez et al. ${ }^{[25]}$ However, it could be observed that the ratios palmitic/linoleic and oleic/linoleic decreased throughout maturation in all modalities and varieties, in accordance with Jiménez et al. ${ }^{[36]}$ and other authors ${ }^{[19]}$ who reported that monounsaturated/polyunsaturated ratios were not influenced by the irrigation level. On the contrary, the linoleic/linolenic ratio increased in both varieties and cultivation modalities as maturation increases, reaching the maximum values in stage IV, and also showed differences between cultivation modalities (more in organic samples).

\section{Conclusions}

In this work, the influence of different aspects, such as the variety, fruit ripening degree, the irrigation and the type of cultivation (conventional and organic), on the quality of the EVOO obtained in similar conditions (geographical area, climate ... etc) have been studied simultaneously, taking into consideration the agronomical and physicochemical parameters, the polyphenols, tocopherols, and fatty acid composition and the volatile and sensory profiles. In the literature, there are similar studies, but they do not consider all these variables simultaneously, nor determine all these physicochemical parameters, and in most cases, olive samples were not obtained under similar conditions.

In addition, among the 85 volatile compounds determined in the samples, 1-hydroxy-2-propanone, (E)-linalool oxide and 2acetylfuran have been described for the first time in olive oil.

The results obtained showed that olive oils differed first according to their variety, secondly to the stage of ripeness of the fruits (the more the greater the ripening degree of the fruit) and finally, within each variety, according to the cultivation modality. Thus, organic irrigation differed markedly from conventional modalities (with and without irrigation), with significant differences being observed in the acidity, stability, tocopherol and polyphenol contents, fatty acid composition and sensory attributes. The variety and the ripening degree of the olives had an effect on all the parameters studied, showing a greater effect on the volatile composition, and, therefore, in their organoleptic characteristics and quality of EVOOs, than the cultivation method (organic or conventional).

Irrigation was the variable that proved to have the least influence on the chemical composition of the olive oils. However, in both varieties, irrigation increased yields.

From a sensorial point of view, the sensory attributes of grass, apple, bitter and pungent, made it possible to differentiate the earliest ripening states of the fruits at the time of harvesting and were consistent with the amounts obtained in total polyphenols, stability, as well as quality parameters. 
According to the results obtained, we can say that the optimal moment of harvesting in the conventional modality would be point III, while for organic oils, their optimal collection would be earlier since they presented a more advanced moment of maturity.

\section{Supporting Information}

Supporting Information is available from the Wiley Online Library or from the author.

\section{Acknowledgements}

The authors are grateful for the funding provided by "Consejería de Economía, Conocimiento, Empresas y Universidad" of the "Junta de Andalucía" (Project P18-TP-2850).

\section{Conflict of Interest}

The authors declare no conflict of interest.

\section{Data Availability Statement}

The data that supports the findings of this study are available in the supplementary material of this article.

\section{Keywords}

conventional cultivation, dryland farming, extra virgin olive oil, irrigation, organic

Received: December 4, 2020

Revised: May 23, 202

Published online: June 25, 2021

[1] MAPAMA. Subdirección General de Calidad Diferenciada y Agricultura Ecológica, Ministerio de Agricultura y Pesca, Alimentación y Medio Ambiente, http://www.magrama.gob.es/es/ agricultura/temas/producciones-agricolas/aceite-oliva-y-aceitunamesa/aceite.aspx. (accessed: December 2020).

[2] A. López-Yerena, J. Lozano-Castellón, A. Olmo-Cunillera, A. TresserraRimbau, P. Quifer-Rada, B. Jiménez, M. Pérez, Molecules 2019, 24, 1986.

[3] A. M. Vidal, S. Alcalá, A. De Torres, M. Moya, J. M. Espínola, F. Espínola, Molecules 2019, 24, 3587.

[4] Official Journal of the European Union, Commission Regulation (EEC) No 2568/91 of 11 July 1991 on the Characteristics of Olive Oil and Olive-Residue Oil and on the Relevant Methods of Analysis, 1991, L248, 1-83. http://www.fao.org/faolex/results/details/en/ c/LEX-FAOC040621/ (accessed: December 2020).

[5] Official Journal of the European Union, European Union (EU). Commission Regulation (EU) No. 432/2012 of 16 May 2012 Establishing a List of Permitted Health Claims Made on Foods, Other than Those Referring to the Reduction of Disease Risk and to Children's Development and Health, 2012, p. 136. https://eur-lex.europa.eu/legal-content/ EN/ALL/?uri=CELEX\%3A32012R0432 (accessed: November 2020).

[6] C. M. Kalua, M. S. Allen, D. R. Bedgood, A. G. Bishop, P. D. Prenzler, K. Robards, Food Chem. 2007, 100, 273.
[7] M. Servili, S. Esposto, R. Fabiani, S. Urbani, A. Taticchi, F. Mariucci, R. Selvaggini, G. F. Montedoro, Inflammopharmacology 2009, 17, 76.

[8] M. Servili, B. Sordini, S. Esposto, S. Urbani, G. Veneziani, I. Di Maio, R. Selvaggini, A. Taticchi, Antioxidants 2014, 3, 1.

[9] F. Mansouri, A. Ben Moumen, S. Aazza, K. Belhaj, M. L. Fauconnier, M. Sindic, H. Serghini Caid, A. Elamrani, Mater. Today: Proc. 2019, 13, 998.

[10] B. Jiménez, A. Rivas, M. L. Lorenzo, A. Sánchez-Ortiz, Flavour Fragrance J. 2017, 32, 294.

[11] M. Benito, J. M. Lasa, P. Gracia, R. Oria, M. Abenoza, A. C. SánchezGimeno, Eur. J. Lipid Sci. Technol. 2012, 114, 558.

[12] A. M. Vidal, S. Alcalá, A. de Torres, M. Moya, F. Espínola, Eur. J. Lipid Sci. Technol. 2019, 121, 1800360.

[13] F. Mansouri, A. Ben moumen, G. Richard, M. L. Fauconnier, M. Sindic, H. Serghini-Caid, A. Elamrani, J. Mater. Environ. Sci. 2015, 6, 2322.

[14] B. Jimenez, A. S. Ortiz, M. L. Lorenzo, A. Rivas, Eur. J. Lipid Sci. Technol. 2014, 116, 1634

[15] E. Stefanoudaki, M. Williams, K. Chartzoulakis, J. Harwood, J. Agric. Food Chem. 2009, 57, 7048.

[16] M. Servili, S. Esposto, E. Lodolini, R. Selvaggini, A. Taticchi, S. Urbani, G. Montedoro, M. Serravalle, R. Gucci, J. Agric. Food Chem. 2007, 55, 6609.

[17] R. Tognetti, R. D’Andria, R. Sacchi, A. Lavini, G. Morelli, A. Alvino, Ann. Appl. Biol. 2007, 150, 169.

[18] R. D'andria, A. Lavini, G. Morelli, L. Sebastiani, R. Tognetti, Plant Biosyst. -Int. J. Dealing Aspects Plant Biol. 2009, 143, 222.

[19] A. Gómez-Rico, M. D. Salvador, G. Fregapane, Food Res. Int. 2009, 42, 1067.

[20] F. Martinelli, B. Basile, G. Morelli, R. d'Andria, P. Tonutti, Sci. Hortic. 2012, 144, 201.

[21] R. Jiménez-Herrera, B. Pacheco-López, J. Peragón, Antioxidants 2019, 8, 294.

[22] D. L. García-gonzález, R. Aparicio-ruiz, M. T. Morales, OLIVEOIL Huile d'olive 2014, 21, D506.

[23] N. Volakakis, E. Kabourakis, C. Leifert, in Olives and Olive Oil as Functional Foods: Bioactivity, Chemistry and Processing, 1st ed.(Eds:Fereidoon Shahidi, Apostolos Kiritsakis) Wiley Online Library, 2017, pp. 35-43.

[24] B. J. Herrera, A. R. Velasco, A. Sánchez-Ortiz, M. L. L. Tovar, M. Ú. Muñoz, R. M. Callejón, E. O. B. De Quirós, Grasas Aceites 2012, 63, 403.

[25] B. Jimenez, A. Sánchez-Ortiz, M. L. Lorenzo, A. Rivas, J. Am. Oil Chem. Soc. 2015, 92, 1491.

[26] M. Uceda, L. Frias, in Proceeding of II Seminario Oleícola Internacional, Ineternational Olive Oil Council, Córdoba 1975, pp. 125-130.

[27] Aenor Asociación Española de Normalización y Certificación, Materias Grasas. Humedad y Materias Volatiles (Método de La Estufa de Aire). Norma UNE 55-020-73, Madrid, España, 1973. https://www.une.org/encuentra-tu-norma/buscatu-norma/norma?c=N0005665 (accessed: June 2020).

[28] Aenor Asociación Española de Normalización y Certificación. Cuerpos Grasos. Determinación Del Contenido En Material Grasa Total de La Aceituna. Norma UNE 55030, Madrid, España, 1961. https://www.aenor.com/normas-y-libros/buscador-denormas/UNE? $\mathrm{c}=$ N0005670 (accessed: June 2020).

[29] F. Gutiérrez Rosales, Grasas Aceites 1989, 40, 1.

[30] IUPAC, Standard Methods of Analyses of Oils, Fats and Derivatives, Blackwell, Oxford 1992.

[31] C. Paquot, A. Haufenne, Standard Methods for the Analysis of Oils, Fats and Derivatives, Blackwell Scientific, Oxford 1987.

[32] Official Journal of the European Union, Commission Regulation $640 / 2008 / E C$ of 4 July 2008, Amending Regulation (EEC) No $2568 / 91$ on the Characteristics of Olive Oil and Olive-Residue 
Oil and on the Relevant Methods of Analysis, 2008, L178, 11-16. https://eur-lex.europa.eu/LexUriServ/LexUriServ.do?uri=O): L:2008: 178:0011:0016:EN:PDF (accessed: June 2020).

[33] R. M. Callejón, A. G. González, A. M. Troncoso, M. L. Morales, J. Chromatogr. A 2008, 1204, 93.

[34] M. H. Ryan, J. W. Derrick, P. R. Dann, J. Sci. Food Agric. 2004, 84, 207.

[35] A. Rivas, A. Sanchez-Ortiz, B. Jimenez, J. García-Moyano, M. L. Lorenzo, Eur. J. Lipid Sci. Technol. 2013, 115, 621.

[36] B. Jimenez, R. Callejón, A. Sánchez-Ortiz, E. Ortega, M. L. Lorenzo, A. Rivas, Eur. J. Lipid Sci. Technol. 2014, 116, 1647.

[37] B. Jiménez, A. Sánchez-Ortiz, M. Lorenzo, A. Rivas, Food Res. Int. 2013, 54, 1860.

[38] S. Dabbou, F. Brahmi, R. Selvaggini, H. Chehab, S. Dabbou, A. Taticchi, M. Servili, M. Hammami, Int. J. Food Sci. Technol. 2011, 46, 1964.

[39] A. Rosati, C. Cafiero, A. Paoletti, B. Alfei, S. Caporali, L. Casciani, M. Valentini, Food Chem. 2014, 159, 236.

[40] M. D. Salvador, F. Aranda, G. Fregapane, Food Chem. 2001, 73, 45.

[41] F. Gutiérrez, T. Arnaud, M. A. Albi, J. Am. Oil Chem. Soc. 1999, 76, 617.

[42] A. A. Fernandes-Silva, V. Falco, C. M. Correia, F. J. Villalobos, Grasas Aceites 2013, 64, 59.

[43] M. Morales, R. Aparicio-Ruiz, R. Aparicio, in Handbook of Olive Oil: Analysis and Properties. (Eds:Ramón Aparicio-Ruiz, John Harwood) Springer, New York 2013, p. 261.

[44] P. Ninfali, M. Bacchiocca, E. Biagiotti, S. Esposto, M. Servili, A. Rosati, G. Montedoro, J. Am. Oil Chem. Soc. 2008, 85, 151.

[45] A. Kiritsakis, A. Kanavouras, K. Kiritsakis, Eur. J. Lipid Sci. Technol. 2002, 104, 628 .

[46] N. B. Youssef, W. Zarrouk, A. Carrasco-Pancorbo, Y. Ouni, A. SeguraCarretero, A. Fernández-Gutiérrez, D. Daoud, M. Zarrouk, J. Sci. Food Agric. 2010, 90, 199.

[47] L. Sánchez-Rodríguez, M. Kranjac, Z. Marijanovic, I. Jerkovic, M. Corell, A. Moriana, A. A. Carbonell-Barrachina, E. Sendra, F. Hernández, Molecules 2019, 24, 2148.
[48] F. Magagna, L. Valverde-Som, C. Ruíz-Samblás, L. CuadrosRodríguez, S. E. Reichenbach, C. Bicchi, C Cordero, Anal. Chim. Acta 2016, 936, 245.

[49] F. Angerosa, Eur. J. Lipid Sci. Technol. 2002, 104, 639.

[50] M. García-Nicolás, N. Arroyo-Manzanares, L. Arce, M. HernándezCórdoba, P. Viñas, Foods 2020, 9, 1288.

[51] D. Hhiari, I. H. Suffet, S. Barrett, Water Sci. Technol. 1995, 31, 93.

[52] R. Aparicio, M. T. Morales, D. L. García-González, Eur. J. Lipid Sci. Technol. 2012, 114, 1114.

[53] J. Tous, A. Romero, Variedades de Olivo: con Especial Referencia a Cataluña, Fundación La Caixa, Barcelona, 1993.

[54] M. Gracia, A. Royo, M. Guillén, Grasas Aceites 2009, 60, 321.

[55] F. Gutiérrez, T. Arnaud, M. A. Albi, J. Am. Oil Chem. Soc. 1999, 76, 617.

[56] A. Gómez-Rico, M. D. Salvador, A. Moriana, D. Pérez, N. Olmedilla, F. Ribas, G. Fregapane, Food Chem. 2007, 100, 568.

[57] G. Caruso, R. Gucci, S. Urbani, S. Esposto, A. Taticchi, I. Di Maio, R. Selvaggini, M. Servili, Agric. Water Manage. 2014, 134, 94.

[58] A. Gómez-Rico, G. Fregapane, M. D. Salvador, Food Res. Int. 2008, $41,433$.

[59] M. Greven, S. Neal, S. Green, B. Dichio, B. Clothier, Agric. Water Manage. 2009, 96, 1525

[60] O. Baccouri, M. Guerfel, M. Bonoli-Carbognin, L. Cerretani, A. Bendini, M. Zarrouk, D. Daoud, Riv. Ital. Sostanze Grasse 2009, 86, 173.

[61] M. Issaoui, G. Flamini, H. Chehab, P. CIONI, M. Braham, M. Hammami, J. Food Biochem. 2013, 37, 185.

[62] S. Samman, J. W. Y. Chow, M. J. Foster, Z. I. Ahmad, J. L. Phuyal, P. Petocz, Food Chem. 2008, 109, 670.

[63] J. M. García, A. Morales-Sillero, A. G. Pérez-Rubio, A. Diaz-Espejo, A. Montero, J. E. Fernández, J. Sci. Food Agric. 2017, 97, 1018.

[64] K. Yousfi, R. M. Cert, J. M. García, Eur. Food Res. Technol. 2006, 223, 117.

[65] L. M. Nieto, G. Hodaifa, J. L. Lozano Peña, J. Sci. Food Agric. 2010, 90, 2393. 